\title{
O ELEMENTO DIALÓGICO NO CUIDADO DE ENFERMAGEM: UM ENSAIO COM BASE EM MARTIN BUBER
}

The dialogical element in nursing care:

An attempt based on martin buber

El elemento dialógico en el cuidado de enfermería:

Un ensayo con base en martin buber

Diego Schaurich ${ }^{1}$

Maria da Graça Oliveira Crossetti ${ }^{2}$

\section{RESUMO}

Este estudo configura um ensaio teórico-filosófico que teve como objetivo refletir acerca do elemento dialógico no mundo do cuidado de enfermagem, tendo como fundamentação os pressupostos de Martin Buber. Parte-se da compreensão das raízes históricas do conceito de cuidado como algo inerente ao existir do ser humano, chegando a sua vertente expressiva e profissionalizada - o cuidado de enfermagem - e como o diálogo produz, intermedeia e conduz as relações de cuidar. Finalizase acreditando que o diálogo precisa ser considerado para além de um mecanismo comunicacional, sendo um carreador de significações e sentimentos ao instaurar o encontro de cuidado em enfermagem.

Palavras-chave: Enfermagem. Cuidados de Enfermagem. Filosofia em Enfermagem.

\begin{abstract}
This study represents a theoretical-philosophical attempt to reflect upon the dialogical element in the world of Nursing care supported by Martin Buber's presuppositions. It starts with the historical roots of the care concept as something inherent of the human being's existence, reaching its expressive and professional slope - Nursing care - and how the dialogue produces, intermediates and leads the relationships of caring. Finally, it is believed that the dialogue needs to be considered beyond the communication mechanism, as it carries significance and feelings when the meeting of care in Nursing is established.
\end{abstract}

\section{Resumen}

Este estudio configura un ensayo teórico-filosófico que tuvo como objetivo reflexionar sobre el elemento dialógico en el mundo del cuidado de Enfermería, teniendo como fundamentos los presupuestos de Martin Buber. Se parte de la comprensión de las raíces históricas del concepto de cuidado como algo inherente al existir del ser humano, llegando a su vertiente expresiva y profesionalizada - el cuidado de Enfermería - y cómo el diálogo produce, intermedia y conduce a las relaciones de cuidar. Se termina creyendo que el diálogo precisa ser considerado más que un mecanismo comunicacional, siendo un acarreador de significaciones y sentimientos al instaurar el encuentro de cuidado en Enfermería. 


\section{CONSIDERAÇÕES INICIAIS}

Parte-se da compreensão do conceito de cuidado, de uma busca em suas raízes históricas, como um constructo abrangente e complexo, que apresenta relação com o vivido pelo ser humano. E, a partir dele, chega-se ao cuidado de enfermagem - entendido como vertente expressiva e profissionalizada desse constructo maior - e sua necessidade de dar conta da dinamicidade existente entre o estar saudável e o estar doente.

Para este estudo tomar-se-á como fundamentação 0 conceito de cuidado compreendido ora como arte, apresentando traços estéticos e intersubjetivos, sendo inerente ao vivido e experienciado pelo ser humano em dados tempo e espaço compartilhados com o outro e com mundo, ora como ciência, ou seja, como constructo fundamentado em disciplinas e áreas do conhecimento. A partir desse posicionamento, entende-se que o cuidado de enfermagem precisa abranger, além dos aspectos técnicos e científicos, os preceitos éticos, estéticos, filosóficos, humanísticos, solidários e culturais ${ }^{1,2}$.

Assim, esse cuidado é constituído e permeado por diferentes elementos, como a responsabilidade, as habilidades, as relações interpessoais, os saberes e conhecimentos instituídos, entre outros. Acredita-se, dessa maneira, que, ao revisitar algumas compreensões acerca do cuidado e do cuidado de enfermagem, dando destaque à importância do elemento dialógico como intermediador das relações entre o ser que cuida e o ser cuidado, estar-se-á contribuindo para a construção de saberes na Enfermagem. Portanto, este estudo tem por objetivo refletir acerca do elemento dialógico presente no mundo do cuidado de enfermagem, tendo como fundamentação os pressupostos da filosofia de Martin Buber.

\section{o Cuidado e o Cuidado de Enfermagem}

Atualmente, observa-se que o cuidar/cuidado tem se tornado uma temática explorada e pesquisada por diferentes áreas do saber, como antropologia, filosofia, psicologia, medicina e, em especial, pela Enfermagem. Nesse contexto, compreendese que o cuidado é um constructo amplo e complexo, sendo uma forma de estar-com, de perceber, relacionar-se e preocupar-se com outro ser humano em dados tempo e espaço compartilhados no face-a-face.

Retomando as origens das práticas de cuidado, encontrase que sua preocupação e seu interesse residiam na manutenção da vida, a fim de que os seres pudessem crescer, desenvolver e, assim, dar continuidade a sua espécie. 0 cuidado significava 'tomar conta' e tinha por objetivo garantir as funções imprescindíveis à satisfação das necessidades presentes na vida dos indivíduos, tais como alimentação, hidratação, abrigo, vestimentas, entre outras, assegurando a luta contra a morte ${ }^{3}$.

Compreende-se, dessa forma, que o cuidado fazia (e faz) parte do vivido, cotidianamente, pelos homens, estando relacionado a aspectos de proteção, ou seja, era necessário um abrigo para proteger-se dos inimigos e das intempéries da natureza, da mesma maneira que era necessário alimentar-se e ingerir água para não ficar fragilizado, adoecer e morrer. 0 cuidado, portanto, "é fundamental à vida, faz parte, é inerente à natureza do ser humano. Sem o cuidado não há desenvolvimento, não há auto-realização, levando mesmo essa ausência à perda de sentido e morte"2:105.

Sendo assim, entende-se que o cuidado é o sentido e o significado da existencialidade do ser humano. É por meio do cuidado que o homem faz presença a si e passa a existir diante do outro e do mundo. Faz-se importante salientar, também, que o cuidado, antes mesmo de ser e realizar-se em uma ação, expressa um modo de ser, sentir e viver, estando intrinsecamente relacionado à essência do ser do homem.

Dentre as muitas e diversas maneiras de cuidar existentes, para este momento, pretende-se tecer uma aproximação com algumas definições que caracterizam o cuidado vivido e realizado por aqueles que fazem a Enfermagem acontecer. Contudo, merece ser destacado que o cuidado de enfermagem representa uma vertente expressiva e profissionalizada do cuidado humano, feito por humanos e destinado a humanos, contendo, então, raízes que o confirmam como modo de ser e de existir.

0 cuidado de enfermagem é, também, complexo e dinâmico, envolvendo um modo de ser pessoal e profissional, conhecimentos específicos e atitudes práticas que 0 caracterizam como parte da relação estabelecida entre o ser que cuida e o ser que é cuidado, e destes com o mundo vivido e experienciado por ambos no tempo e espaço compartilhados. Nesse sentido, depreende-se que o cuidado de enfermagem "consiste na essência da profissão e pertence a duas esferas distintas: uma objetiva, que se refere ao desenvolvimento de técnicas e procedimentos, e uma subjetiva, que se baseia em sensibilidade, criatividade e intuição para cuidar de outro ser" $"$ :269.

Dessa maneira, há que se considerar que o cuidado de enfermagem é um encontro entre seres humanos que buscam tornarem-se mais por meio de suas relações de cuidar, objetivando a promoção, manutenção ou recuperação da saúde. E é em virtude da importância que adquiriu e por ser considerado o foco da profissão, que, a partir da década de 1990, difundiu-se e ampliou-se o movimento sobre o cuidar em enfermagem e "se incrementaram as perspectivas teóricas e/ou filosóficas e as pesquisas para a compreensão dos significados de cuidar" ${ }^{\text {"81. }}$.

Estudo atual realizado com pós-graduandos de Enfermagem, que objetivou identificar características do cuidado, revelou que existem tipos diferentes de cuidado (percebidos como ação, como atividade de enfermagem, como subjetividade e como interação), que se desenvolvem em diversos espaços/cenários, para o qual existem seres envolvidos e dimensões específicas de cuidar (da humanização, da espacialidade, da sistematização, da ecologia e da cultura do cuidado). Em virtude dessas percepções e compreensões, acredita-se que o cuidado é dinâmico, solidário, interativo, técnico-científico, criativo e caracteriza o trabalho da Enfermagem ${ }^{6}$. 
As diferentes concepções e apropriações do cuidado também foram o foco de outra pesquisa ${ }^{7}$ que analisou as teses brasileiras de Enfermagem produzidas entre 2001 e 2003. Esse processo revelou 13 subunidades sobre a temática, das quais destacamse o cuidado humanístico, o cuidado transdimensional, o cuidado solidário, o autocuidado, o cuidado cultural, a estética do cuidado e o cuidado dialógico. Especificamente em relação a este último, vale ressaltar que

el diálogo en las relaciones de cuidado es evidenciado no sólo como estrategia comunicativa, sino también como um constructo que converge y concentra el proprio cuidado, mostrándose como estructura y propriedad del cuidado, como contenido y forma, como procesos y contra-procesos de dialogicidad, implicando um pensar abierto, creativo y ético ${ }^{7: 41}$.

Ao encontro dessas investigações e, ao buscar compreender as especificidades do cuidar na Enfermagem, um estudo realizado com enfermeiros/as de um hospital-escola constatou que existem cuidados de natureza propedêutica (relacionados às ações educativas) e de natureza terapêutica (referentes à organização do ambiente de cuidar, à expressividade do ser, à sistematização do cuidar e às interfaces presentes no cuidar). Isso porque o cuidado apresenta constructos que envolvem a ciência e a arte da Enfermagem, acontecendo em um mundo em que os seres do cuidar coexistem em constante relação e (inter)dependência ${ }^{8}$.

Nesse sentido, e por se entender que os conceitos e as descrições do cuidado de enfermagem estão em continuum vira-ser e movimento, percebe-se que existem elementos que 0 sustentam e o constituem, como o afeto, o respeito, a responsabilidade, o diálogo, o prazer, o conforto físico, a troca de energia, as relações humanas, a criatividade, as habilidades, os conhecimentos, entre outros. Em meio a esses múltiplos elementos, para este momento, far-se-á um recorte em relação ao aspecto dialógico presente no cuidado, tendo como fundamentação o referencial filosófico de Martin Buber ${ }^{9,10}$.

\section{O Dialógico no Pensamento de Buber}

O filósofo judeu Martin Buber (1878-1965) desenvolveu uma obra cujo pensamento não pode, de modo delimitado e precipitadamente, ser vinculado a nenhuma corrente filosófica, pois sua preocupação fundamental foi elaborar pressupostos que estivessem em movimento cíclico, isto é, que permitissem uma co-responsabilidade entre a reflexão e a ação, entre 0 logos e a práxis, entre o vivido e o experienciado. Contudo, é possivel perceber uma relação entre sua filosofia e a corrente epistemológica da fenomenologia, uma vez que sofreu influência de pensadores como Feuerbach, Kierkegaard, Friedman e outros ${ }^{11}$.

Pode-se considerar que a filosofia de Martin Buber é relacional-dialógica, uma vez que estes representam dois conceitos centrais desenvolvidos ao longo de suas obras, ou seja, apresentam como fator primordial as relações existentes entre os seres humanos e a palavra como sendo dialógica. Nesse sentido, percebe-se que suas idéias estão interessadas e voltadas para o sentido da existência do ser do homem em todas as suas manifestações, além de propiciar uma reflexão da reflexão e despertar para um compromisso com a experiência vivida, com a vida ${ }^{9,10}$.

Entende-se que a condição de existência como ser-nomundo é a palavra como diálogo e, portanto, o mundo é múltiplo para o homem, podendo este assumir uma das três possibilidades de existir: poderá adentrar de forma autêntica na relação instaurada pela palavra-princípio EU-TU; poderá experienciar o relacionamento objetivante da palavra-princípio EU-ISSO ou poderá adentrar ao fenômeno puro e autêntico estabelecido pela palavra-princípio EU-TU Eterno. Isso porque é por meio da palavra "que o ser do homem adentra à existencialidade, uma vez que ela contém o vivido, é dialógica. É a palavra que situa o homem no mundo com o outro, que 0 mantém no ser, que faz do ser, homem"12:35.

Faz-se, contudo, importante salientar que as palavrasprincípio EU-TU e EU-ISSO são atitudes fundamentais ao ser do homem, para sua existência. A primeira representa uma forma de presentificação, de encontro, de relação entre dois seres que estão abertos e disponíveis para, recíproca e mutuamente, se atualizarem existencialmente, enquanto que a segunda é essencial para a construção e elaboração do saber, do conhecimento, da ciência que rege o mundo vivido e experienciado ${ }^{13}$.

Essas atitudes existenciais acontecem por meio da palavra, por meio do dialogal, pois o homem não conduz a palavra, mas é ela que o mantém no ser; a palavra proferida é uma atitude eficaz, efetiva e atualizadora do ser do homem. No entanto, há que se considerar que o diálogo não pode ser compreendido como uma categoria do raciocínio dedutivo, mas é essencialmente um evento, e como tal ele acontece entre os seres humanos ${ }^{9,10}$.

A palavra, então, precisa ser proferida em busca do diálogo, pois ela não quer meramente ser dita, lida e interpretada, mas quer, essencialmente, ser emanada, ouvida e respondida. A palavra é significativa porque está profundamente comprometida com o EU, com o TU e com o mundo do 'entredois'. 0 diálogo somente pode acontecer na relação entre dois seres, sendo o 'entre-dois' uma "esfera não espacial, mas, sim, ontológica, que será condição de possibilidade de toda relação dialógica inter-humana"11:117.

Nesse sentido, a palavra, após ser proferida pelo EU no encontro com o seu TU, deixa de pertencer a ele e também não pertence ao outro, mas passa a localizar-se no 'entre-eles', na relação EU-TU; o 'entre' é o intervalo, o lugar de revelação da palavra proferida. Faz-se importante, ainda, salientar que 0 diálogo autêntico somente ocorrerá entre o EU e o TU no momento em que cada um vir e perceber o outro em sua alteridade, como essencialmente é, como genuinamente se apresenta como ser-no-mundo.

Sendo assim, há que se considerar que a relação EU-TU é um encontro existencial em que estão presentes a 
reciprocidade, a intersubjetividade, o estar-com-o-outro genuinamente no tempo e no espaço compartilhados. Essa atitude mostra um modo dialógico de ser e existir, no qual a palavra proferida pelo EU recebe a resposta do TU e, então, a resposta é responsabilidade de um TU para com a palavra invocada pelo EU. A relação EU-TU revela o "voltar-se-para-ooutro" sendo dialógica, ao passo que o relacionamento EUISSO desvela-se pelo "dobrar-se-em-si-mesmo", ou seja, um modo monológico de ser" ${ }^{10: 57}$.

Dessa forma, por ser o diálogo uma das condições de existência para o homem e por estar diretamente relacionado às vivências e relações estabelecidas no e com o mundo, é que se acredita em sua significação como modo de ser, estar e (con)viver. Portanto, refletir sobre os diálogos presentes nas relações que se constituem no mundo do cuidado revela-se uma maneira de entender a complexidade que envolve os encontros entre seres humanos durante o evento de cuidar em Enfermagem.

\section{O Elemento Dialógico no Cuidado de Enfermagem}

A Enfermagem pode ser considerada ciência e arte na área da saúde, uma disciplina humana do fazer-com e estar-com que precisa aliar o avanço técnico-científico, as normas e rotinas, os procedimentos e técnicas, à intersubjetividade, à presença autêntica e genuína, ao diálogo vivido e à disponibilidade de um modo de ajuda ${ }^{1}$. 0 cuidado representa uma das maneiras que a Enfermagem tem para manifestar-se como ciência-arte e é constituído por diversos elementos que caracterizam o saber e o fazer da profissão.

Ao elaborarem a Teoria de Enfermagem Humanística, Paterson e Zderad ${ }^{1}$ subsidiaram-se na filosofia buberiana e, a partir desta construção, passaram a compreender a Enfermagem como um diálogo vivo, ou seja, entendem a Enfermagem como um modo dialogal de ser e de existir em uma determinada situação intersubjetiva. Assim, os diálogos que se produzem emanam de um chamado e uma resposta, e conduzem ao cuidado que é entendido como um evento relacional-dialógico entre seres humanos. A Enfermagem é um modo especial de diálogo humano.

0 cuidado de enfermagem, então, é um encontro vivido e dialogado entre o ser que cuida e o ser que é cuidado, em que estão presentes tudo o que um ser é e não é, suas possibilidades de ser mais, suas limitações em não-ser e suas potencialidades para estar-melhor no mundo da vida. Para que este encontro aconteça, faz-se necessário que existam um ser com disponibilidade para ajudar e um ser que necessite de ajuda, e que ambos estejam abertos à relação dialógica com o outro, pois entende-se que é o diálogo que conduz ao cuidado ${ }^{13}$.

Compreende-se, portanto, que o diálogo configura um dos elementos que instauram o cuidar, uma vez que é por intermédio dele que o ser que cuida, ao ser chamado pelo ser que necessita de ajuda, reconhece esse apelo existencial e responde por meio do cuidado. 0 cuidado revela-se uma resposta humana a um pedido de ajuda e ocorre quando os seres que fazem parte deste mundo do cuidar estão envolvidos, comprometidos, co-responsabilizados e presentes no face-aface com o outro.

Nesse sentido, o cuidado emana como resposta a um chamado, e, assim, instaura-se a relação dialógica em que estão presentes a inter-subjetividade e o inter-humano, pois o ser que cuida e o ser que é cuidado passam a vivenciar sentimentos, emoções, percepções, valores em comum e têm objetivos também compartilhados, em uma esfera que acontece entre eles. "A enfermagem é um modo dialogal de ser em uma situação intersubjetiva, na qual um indivíduo distinto e único entra em relação com outro"14:32.

No entanto, para ser considerado um elemento que constitui e institui o cuidado de enfermagem, o diálogo precisa ser percebido para além de um mero mecanismo psicológico ou meio de comunicação entre os seres humanos, bem como precisa deixar de ser um conceito construído no plano abstrato das idéias, para constituir-se na vida em si e descrever as experiências humanas ${ }^{10}$. Sendo assim, tomar-se-á uma situação prática presente no mundo do cuidar como exemplo, a fim de melhor refletir acerca da dialogicidade na Enfermagem, qual seja: a revelação do diagnóstico.

0 ato de revelar o diagnóstico (independentemente do tipo de doença) é um fenômeno presente nos serviços de saúde e que envolve um encontro entre o ser que cuida e o ser que é cuidado, portanto de interesse para a Enfermagem. É necessário, dessa forma, considerá-lo como uma situação que merece atenção e para a qual é preciso desenvolver cuidados que levem em consideração componentes presentes no diálogo que se estabelece entre eles.

Compreende-se que a revelação de um diagnóstico representa mais do que a comunicação de um estado de saúde ou de doença, sendo, também, um modo de manifestar seu ser e existir no mundo e que se dará por meio do diálogo no encontro de cuidado. Contudo, o ser que cuida precisará estar atento não só ao resultado (clínico-laboratorial) que será comunicado, mas também à maneira como será expresso, à gestualidade que acompanha este momento e às palavras que serão emanadas, pois elas apresentam sentidos e geram sentimentos diferentes para cada ser. Corrobora-se, assim, o entendimento de que

nossa maneira de compreender as palavras foi como que embrutecida pelo uso, tornando-nos insensíveis para o seu sentido primordial. Então em certo sentido elas nos chocam, como a verdade nos incomoda às vezes pelo brilho de sua luz ${ }^{15: L x X I I I}$.

A partir deste exemplo, pode-se perceber a relevância do elemento dialógico para instaurar o cuidado de enfermagem, uma vez que ele não é apenas um ato comunicativo isolado em 
si, mas um carreador de palavras que contêm significações específicas e que geram sentimentos únicos de acordo com cada ser que participa desse encontro existencial. Isso tanto mais importância adquire quando consideramos as complexas situações presentes na área da saúde, como o comunicar o estado terminal para um familiar, o informar que o outro é portador de uma doença crônica ou o revelar que tem uma doença maligna.

0 diálogo, desta maneira, representa um dos elementos primordiais ao mundo do cuidar de enfermagem, pois está presente em diferentes situações práticas da profissão e intermedeia as relações entre os seres que cuidam e os que são cuidados. Em virtude disso, acredita-se na necessidade de lançar um olhar especial a este elemento em termos de compreender seus significados, bem como perceber e refletir (criticamente) como ele está arraigado e permeando os encontros de cuidado, com vistas a se alcançar um cuidar que se quer humanístico, ético, estético e solidário.

\section{CONSIDERAÇÕES REFLEXIVAS}

0 cuidado e a história humana apresentam intrínsecas aproximações, uma vez que estão (inter)relacionados e, de certa forma, são interdependentes no sentido de se poder compreender que a existência humana se desvela e se mantém por meio das diversas vivências e experiências de cuidar. Como vertente expressiva e profissionalizada deste constructo mais amplo, encontra-se o cuidado de enfermagem, que se manifesta e se revela em diferentes encontros entre seres humanos e é constituído e instituído por múltiplos elementos, dentre eles o dialógico, foco deste ensaio.

Assim, à luz do referencial filosófico de Martin Buber ${ }^{9,10}$, entende-se que é o elemento dialógico o que possibilita que 0 cuidado de enfermagem se presentifique entre os seres; é a partir de uma necessidade de ajuda emanada por um ser humano por meio de um chamado que o cuidar acontece como resposta a este pedido existencial. Nesse sentido, há que se vislumbrar que o diálogo precisa ser compreendido para além de um mero mecanismo comunicacional presente na prática da profissão, mas como um elemento carreador de um modo de ser e de existir e, conseqüentemente, de cuidar.

Portanto, o cuidado de enfermagem é um encontro entre seres com o intuito de alcançar melhores condições de saúde e para a morte, que se sustenta, dentre outros elementos, pelo dialógico. Cabe ao ser que cuida, dessa maneira, estar atento aos muitos movimentos, sentidos e significações que acontecem e se produzem durante o diálogo em Enfermagem, sendo este um dos elementos através dos quais o cuidado se torna humanístico, possibilite a superação paradigmática em direção a um modelo holístico e potencialize o vir-a-ser dos indivíduos, com vistas a melhores condições de vida.

\section{Referências}

1 Paterson J, Zderad L. Humanistic nursing. New York (USA): National League for Nursing; 1988.

2 Souza MF. Abordagens do cuidado na enfermagem. Acta Paul Enferm 2000; 13(n esp 1): 98-106.

3 Collière MF. Promover a vida: da prática das mulheres de virtude aos cuidados de enfermagem. Lisboa (P0): Sindicato dos Enfermeiros Portugueses; 1989.

4 Souza ML, Sartor VVB, Padilha MICS, Prado ML. 0 cuidado em Enfermagem: uma aproximação teórica. Texto\&Contexto Enferm 2005 abr/jun; 14(2): 266-70.

5 Neves EP. As dimensões do cuidar em enfermagem: concepções teórico-filosóficas. Esc Anna Nery Rev Enferm 2002dez; 6 (supl. 1): 79-92.

6 Erdmann AL, Nascimento KC, Marcelino G, Ribeiro JA. As interfaces do cuidado pelo olhar da complexidade: um estudo com um grupo de pós-graduandos de enfermagem. Esc Anna Nery Rev Enferm 2005 dez.; 9(3): 411-20.

7 Erdmann AL, Leite JL, Mendes IAC, Trevizan MA, Dantas CC. Análisis de investigaciones brasileñas enfocadas en el cuidado de enfermería, años 2001-2003. Cienc Enferm 2005; 11(2): 35-46.

8 Crossetti MG0, Buógo M, Kohlrausch E. Ações de cuidar na enfermagem de natureza propedêutica e terapêutica e suas interfaces com os atos de outros profissionais. Rev Gaúcha Enferm 2000 jan; 21(1): 44-67.

9 Buber M. Eu e tu. $5^{\text {a }}$ ed. São Paulo (SP): Moraes; 1977.

10 Buber M. Do diálogo e do dialógico. São Paulo (SP): Perspectiva; 1982.

11 Von Zuben NA. Martin Buber: cumplicidade e diálogo. Bauru (SP): EDUSC; 2003.

12 Schaurich D, Padoin SMM, Motta MGC. Experienciando um marco conceitual para o cuidado em Enfermagem ao ser-familiar e/ou cuidador e ao ser-criança. Rev Cogitare Enferm 2003 jul/dez; 8(2): 34-43.

13 Schaurich D. Ser familiar cuidadora de uma criança com aids: compreensões à luz da filosofia de Martin Buber. [dissertação de mestrado]. Programa de Pós-Graduação em Enfermagem/ UFRGS. Porto Alegre (RS); 2007. $139 \mathrm{f}$.

14 Fenili RM, Santos OMB. Analisando a teoria humanística de Paterson e Zderad para vislumbrar a enfermagem como diálogo vivo. Nursing 2001 ago; 4(39): 30-34.

15 Von Zuben NA. Introdução. In: Buber M. Eu e Tu. $5^{a}$ ed. São Paulo (SP): Moraes; 1977. 